\title{
EFFECTS OF FELDSPAR CONTAMINATION ON EQUIVALENT DOSE AND THE SHAPE OF GROWTH CURVE FOR OSL OF SILT-SIZED QUARTZ EXTRACTED FROM CHINESE LOESS
}

\author{
ZHONGPING LAI ${ }^{1,2}$ and HELMUT BRÜCKNER ${ }^{2}$ \\ ${ }^{1}$ Luminescence Dating Laboratory, QingHai Institute of Salt Lakes, Chinese Academy of Sciences, \\ XiNing 810008, P.R. China \\ ${ }^{2}$ Faculty of Geography, University of Marburg, \\ D-35032 Marburg, Germany
}

\begin{abstract}
This study examines the effects of feldspar contamination of different extent (by fluorosilicic acid etching for different time periods and mixing pure quartz with different percentage of unetched grains) on blue-light stimulated luminescence (BLSL) of quartz (38-63 $\mu \mathrm{m})$ for Chinese loess. In particular, the $D_{e}$ values and the shape of growth curves will be examined. The results show that: (1) The $D_{e}$ determined using feldspar in Chinese loess is obviously underestimated, and infra-red stimulated luminescence (IRSL) has a greater underestimation than BLSL. For aliquots with no fluorosilicic acid etching, an IRSL $D_{e}$ underestimation of $\sim 30 \%$ is observed for a sample with an expected age of $\sim 22 \mathrm{ka}, \sim 19 \%$ underestimation for BLSL, and $\sim 10 \%$ for post-IR BLSL. For quartz BLSL, the contamination of feldspar, which has not dissolved by fluorosilicic acid etching, will inevitably lead to age underestimation. We suggest that the IR-checking should be performed for every single aliquot. An aliquot should be excluded from the final $D_{e}$ calculation if obvious IRSL signal was observed. (2) For the sample under examination blue LED stimulation can reset both IRSL and BLSL signals of feldspars, while IR stimulation cannot reset the BLSL of feldspars. (3) For multiple-mineral aliquot the growth curve shape of the post-IR BLSL is different from that of the IRSL, and within $25 \mathrm{~Gy}$ it is identical to that of the pure quartz BLSL. The contamination of feldspars in quartz will change the shape of a growth curve for quartz BLSL.
\end{abstract}

Keywords: BLSL, IRSL, equivalent dose, Chinese loess, quartz luminescence, feldspar luminescence.

\section{INTRODUCTION}

Judging by the saturation dose level, feldspars should be able to date loess samples much older than $100 \mathrm{ka}$, but this is often not the case. The reason is most likely anomalous fading (Wintle, 1973). Compared to feldspars, quartz luminescence properties are simpler and well known, and - most importantly - quartz luminescence does not show anomalous fading (Krbetschek et al., 1997). Thus, quartz is considered a better dosimeter for luminescence dating. However, for some samples, it is difficult to remove effectively feldspars in order to isolate pure quartz during sample preparation. Therefore specific

Corresponding author: Z. Lai e-mail: zplai@isl.ac.cn

ISSN 1897-1695 (online), 1733-8387 (print) (C) 2008 GADAM Centre, Institute of Physics, Silesian University of Technology.

All rights reserved. procedures have to be adopted in order to wash away signals from feldspars (Jain and Singhvi, 2001; Roberts and Wintle, 2001; Wallinga et al., 2002). A double-SAR protocol is often suitable for this purpose, and involves stimulation of the same aliquot with infra-red (IR) light followed by blue- and green-light (Banerjee et al., 2001). The IR stimulation is intended to reduce the blue/green light stimulated luminescence contribution from feldspars, which normally have a much higher luminescence sensitivity than quartz. Consequently, the equivalent doses for both Infra-red stimulated luminescence (IRSL) and post-IR blue-light stimulated luminescence (BLSL) can be obtained for the same aliquot.

Contradictory results exist with respect to the effects of feldspar contamination on the $D_{e}$ of quartz optically stimulated luminescence (OSL) for Chinese loess sam- 
ples. Using a double-SAR protocol, Roberts and Wintle (2001) reported that values of $D_{e}$ from IRSL measurements are always greater than for the (post-IR) OSL signal using fine grain $(4-11 \mu \mathrm{m})$ multi-minerals (samples from Duowa section in the western edge of the Chinese Loess Plateau); they proposed that sensitivity changes relating to either (or both) natural signals may not be correctly monitored. Also using a double-SAR protocol, Watanuki et al. (2003) concluded that even after correction for laboratory fading both IRSL and post-IR blueOSL ages of multi-minerals underestimate the age of pure quartz OSL (samples from both Urumqi in Xinjiang Province in the west of China and Zhenjiang section in the Yangtze delta, Jiangsu Province in the east coast of China). The main purpose of the study is to examine the effects of feldspar contamination on OSL of quartz for Chinese loess. In particular, the $D_{e}$ values and the shape of growth curves will be examined. The sample was thus prepared so that feldspar contamination had different extent (by fluorosilicic acid etching for different time periods and mixing pure quartz with different percentage of un-etched grains). Because it is difficult to extract pure quartz for fine grains $(4-11 \mu \mathrm{m})$ and there are only few grains larger than $90 \mu \mathrm{m}$ in loess samples, the coarse siltsized quartz (38-63 $\mu \mathrm{m})$ is used for $D_{e}$ determination (Lai and Wintle, 2006; Lai et al., 2007a).

\section{SAMPLE PREPARATION AND MEASURE- MENT TECHNIQUES}

The selected sample is from the classical Luochuan section in the Chinese Loess Plateau, collected in the loess layer L1 which was deposited during the Last Glaciation with an expected age of $\sim 22 \mathrm{ka}$.

The sample was treated using $\mathrm{HCl}$ and $\mathrm{H}_{2} \mathrm{O}_{2}$, and the 38-63 $\mu \mathrm{m}$ grain-size fraction was separated by sieving. This fraction was divided into four parts. These parts were treated with $35 \%$ fluorosilicic acid $\left(\mathrm{H}_{2} \mathrm{SiF}_{6}\right)$ for different time periods of 0 days, 3 days, 6 days and 14 days. After 14 days, all feldspar grains were dissolved and pure quartz was obtained. The purity of quartz was checked using routine IR stimulation. No IRSL signal was detected for pure quartz fraction.

Experiments were carried out using a Risø TL-DA-15 reader, incorporating blue diodes $(\lambda=470 \pm 20 \mathrm{~nm})$ and an IR laser diode $(\lambda=830 \pm 10 \mathrm{~nm})$. Luminescence measurements were made at $130^{\circ} \mathrm{C}$ for $60 \mathrm{~s}$, and the signal was detected using two $3 \mathrm{~mm}$ thick U-340 filters (detection window 275-390 nm). A test dose of $11 \mathrm{~Gy}$ was applied. Irradiations were carried out using a ${ }^{90} \mathrm{Sr} /{ }^{90} \mathrm{Y}$ beta source attached to the Risø reader. Signals from the first $0.96 \mathrm{~s}$ stimulation were integrated for analysis after background subtraction.

Both SAR (Murray and Wintle, 2000) and DoubleSAR (Banerjee et al., 2001; Roberts and Wintle, 2001) protocols were used for $D_{e}$ determination, with a preheat at $260^{\circ} \mathrm{C}$ for $10 \mathrm{~s}$, and a cut-heat at $220^{\circ} \mathrm{C}$ for $10 \mathrm{~s}$. Thus, the $D_{e}$ for BLSL (by SAR), and the $D_{e}$ 's for both IRSL and post-IR BLSL (by double SAR) were obtained.

\section{LABORATORY KNOWN DOSE RECOVERY TESTS}

Murray and Wintle (2003) suggested that a robust protocol for $D_{e}$ measurement must be able to recover a known laboratory dose, and that the ratio of the measured dose to the given laboratory dose, which should be unity, provided a more stringent test than that of the recycling ratio that was part of the SAR protocol. This test investigates the combined function of all the conditions of the procedure, such as preheat, size of test dose, etc. In a laboratory dose recovery test, the known laboratory dose is applied following the complete bleaching of an aliquot and prior to any thermal treatment in the laboratory. The known dose thus mimics the natural dose. The aliquot is then treated as natural sample to obtain $D_{e}$.

For both fractions, namely, the pure quartz (that after 14 days fluorosilicic acid etching; the ratio of un-etched grains to pure quartz grains is $0: 1$ ) and the un-etched quartz (that without fluorosilicic acid etching; the ratio of un-etched grains to pure quartz grains ratio is 1:0), the natural aliquots were bleached at room temperature for $60 \mathrm{~s}$ by IR stimulation, and subsequently for $60 \mathrm{~s}$ by blue stimulation. They were then given a laboratory dose of $60 \mathrm{~Gy}$, then treated as natural aliquots for $D_{e}$ determination. For the un-etched fraction, containing both quartz and feldspars, both double-SAR (for 6 aliquots) and SAR protocols (for another 6 aliquots) were used, to obtain $D_{e}$ 's for IRSL and post-IR BLSL by double-SAR, and BLSL by SAR; for the pure quartz fraction, only SAR was used to obtain $D_{e}$ for BLSL only (6 aliquots; Table 1).

Further experiments were carried out in order to examine the laboratory dose recovery test for aliquots with feldspar contamination of different extents. The unetched fraction was mixed with the purified quartz in ratios (un-etched grains to pure quartz grains) of 1:1, 1:4, and $1: 10$. For each fraction, six aliquots were used, and the final result was the average of the six aliquots. All results are shown in Table 1. For fractions with abovementioned ratios of 1:0 and 1:10, the recovered $D_{e}$ 's for IRSL are 55.1 \pm 1.1 and 55.4 \pm 1.9 Gy, respectively, suggesting that the current difference in the extent of feldspar contamination has no significant effect on the recovered

Table 1. Results for laboratory dose recovery test.

\begin{tabular}{cccc}
\hline \multirow{2}{*}{ Etching days } & \multicolumn{4}{c}{ Recovered $D_{\mathrm{e}}$ of 60 Gy lab dose (Gy) } \\
\cline { 2 - 4 } & IRSL & Post-IR BLSL & BLSL \\
\hline 0 & $55.1 \pm 1.1$ & $56.6 \pm 4.2$ & $56.2 \pm 1.2$ \\
14 & - & - & $57.6 \pm 1.6$ \\
\hline Ratio of unetched grains to & & & \\
quartz grains & & & \\
\hline $1: 0$ & $55.1 \pm 1.1$ & $56.6 \pm 4.2$ & $56.2 \pm 1.2$ \\
$1: 1$ & $54.8 \pm 1.9$ & $56.6 \pm 1.5$ & $56.5 \pm 1.6$ \\
$1: 4$ & $55.3 \pm 1.5$ & $54.7 \pm 2.7$ & $55.3 \pm 2.1$ \\
$1: 10$ & $55.4 \pm 1.9$ & $56.3 \pm 1.2$ & $56.0 \pm 1.3$ \\
Average & $55.2 \pm 0.2$ & $56.1 \pm 0.5$ & $55.8 \pm 0.3$ \\
& & & \\
$0: 1$ & - & - & $57.6 \pm 1.6$ \\
\hline
\end{tabular}


$D_{e}$ 's. Similar results can be seen for post-IRSL and BLSL. The average recovered $D_{e}$ for fractions with above-mentioned ratios of $1: 0,1: 1,1: 4$, and $1: 10$ is $55.2 \pm 0.2$ Gy for IRSL, 56.1 \pm 0.5 Gy for post-IR BLSL, and $55.8 \pm 0.3$ Gy for BLSL; for the pure quartz fraction (etched for 14 days), the recovered BLSL $D_{e}$ is $57.6 \pm 1.6$ Gy (with 4\% underestimation). For all laboratory dose recovery tests, the underestimation of the given dose does not exceed $8.2 \%$ and hence we regard all results of recovery tests as acceptable.

\section{EFFECTS ON $D_{e}$ VALUES}

For the determination of the natural $D_{e}$, the same procedures, as those used in the laboratory dose recovery tests, were applied to two divisions: (A) with different ratios of un-etched to pure quartz grains (1:0, 1:1, 1:4, $1: 10$, and $0: 1$ ); and (B) with different fluorosilicic acid etching times ( 0 days, 3 days, 6 days, and 14 days). Six aliquots were used for each fraction. The result is the average of the six aliquots (Table 2).

For both divisions, the BLSL $D_{e}(79.1 \pm 4.3 \mathrm{~Gy})$ of the pure quartz is the highest, and the post-IR BLSL (quartzdominated signal) $D_{e}$ is higher than that of both the IRSL and BLSL. The BLSL $D_{e}$ increases with increasing etching time (which corresponds to decreasing feldspar content) for (B). But for (A), this trend is not obvious, which may imply that even with a $10 \%$ un-etched grain contamination (ratio of un-etched grains to pure quartz grains is $1: 10$ ) the BLSL signal is still dominated by feldspars. The average of all IRSL $D_{e}$ 's is $55.6 \pm 1.3 \mathrm{~Gy}$, having $\sim 23.5$ Gy or $30 \%$ underestimation compared with the pure quartz BLSL $D_{e}(79.1 \pm 4.3 \mathrm{~Gy})$. The average of all post-IR BLSL $D_{e}$ 's is $70.6 \pm 0.9$ Gy with $\sim 10 \%$ underestimation; and the average of all BLSL (except for the pure quartz fraction) $D_{e}$ 's is $63.7 \pm 3.0$ Gy with $\sim 19 \%$ underestimation. Given that the environmental dose rate will be higher for feldspars than for quartz due to the internal dose and the higher alpha efficiency, the extent of age underestimation for feldspars will be greater than that of the $D_{e}$ values. The reason for the underestimation should be related to anomalous fading of feldspars. For loess samples from the Chinese Loess Plateau, Buylaert et al. (2007) observed anomalous fading in every sample examined, and the overall average value of $g_{2 \text { days }}$ for their samples is $3.10 \pm 0.13 \%$ per decade. For quartz BLSL, the contamination of feldspars will inevitably lead to $D_{e}$, and
Table 2. Results of $D_{e}$ determination.

\begin{tabular}{cccc}
\hline $\begin{array}{c}\text { Ratio of unetched grains to } \\
\text { quartz grains }\end{array}$ & \multicolumn{3}{c}{$\mathrm{D}_{\mathrm{e}}(\mathrm{Gy})$} \\
\cline { 2 - 4 } & IRSL & Post-IR BLSL & BLSL \\
\hline $1: 0$ & $51.2 \pm 0.7$ & $69.0 \pm 2.7$ & $57.8 \pm 0.9$ \\
$1: 1$ & $55.5 \pm 3.9$ & $68.3 \pm 1.6$ & $60.2 \pm 1.3$ \\
$1: 4$ & $56.3 \pm 1.6$ & $70.5 \pm 4.1$ & $62.4 \pm 1.8$ \\
$1: 10$ & $59.2 \pm 0.8$ & $69.8 \pm 3.8$ & $62.1 \pm 1.1$ \\
$0: 1$ & - & - & $79.1 \pm 1.5$ \\
\hline Etching days & & & \\
0 & $51.2 \pm 0.7$ & $69.0 \pm 2.7$ & $57.8 \pm 0.9$ \\
3 & $56.7 \pm 2.3$ & $74.1 \pm 1.6$ & $61.0 \pm 1.7$ \\
6 & $58.9 \pm 3.5$ & $73.4 \pm 2.1$ & $70.2 \pm 1.6$ \\
14 & - & - & $79.1 \pm 4.3$ \\
\hline \multicolumn{4}{|c}{}
\end{tabular}

thus age, underestimation, even if an IR treatment is involved in order to reduce the influence of feldspars. As a result, IR-checking should be performed for every single aliquot at the end of SAR procedures when a $D_{e}$ is determined. An aliquot should be excluded from the final $D_{e}$ calculation if any obvious IRSL signal is observed.

The greater underestimation of IRSL than BLSL of feldspars may imply that the IRSL may have larger anomalous fading rate. It is difficult to directly evaluate if the IR can reset the BLSL of feldspars in loess samples, as quartz also contributes to the BLSL signal. However, Duller and Bøtter-Jensen (1993) demonstrated that IR stimulation was not able to reset the green light stimulated luminescence (GLSL) of sedimentary feldspars, although green light stimulation was able to reduce both IRSL and GLSL signals to the same level. They observed that the GLSL signal decreased to $13 \%$ of the initial value after exposure to IR light for $6000 \mathrm{~s}$. A similar phenomenon has also been observed by others (Galloway, 1994; Banerjee et al., 2001; Blair et al., 2005).

In the following experiment, a natural aliquot of unetched grains was stimulated by blue LED stimulation for $60 \mathrm{~s}$ at $130^{\circ} \mathrm{C}$, then stimulated immediately by IR for $60 \mathrm{~s}$ at $130^{\circ} \mathrm{C}$; another aliquot of un-etched grains was stimulated by IR stimulation for $60 \mathrm{~s}$ at $130^{\circ} \mathrm{C}$, then stimulated immediately by blue LED for $60 \mathrm{~s}$ at $130^{\circ} \mathrm{C}$. After blue LED stimulation, the IRSL has been reduced to background level (Fig. 1a); while after IR stimulation, the BLSL signal is still very strong (much stronger than IRSL, Fig.1b). Due to multiple-mineral composition of our samples, it is not certain to conclude that IR stimulation can't reset the BLSL signal of feldspars as quartz grains also contribute BLSL signals. However, the $\sim 10 \%$
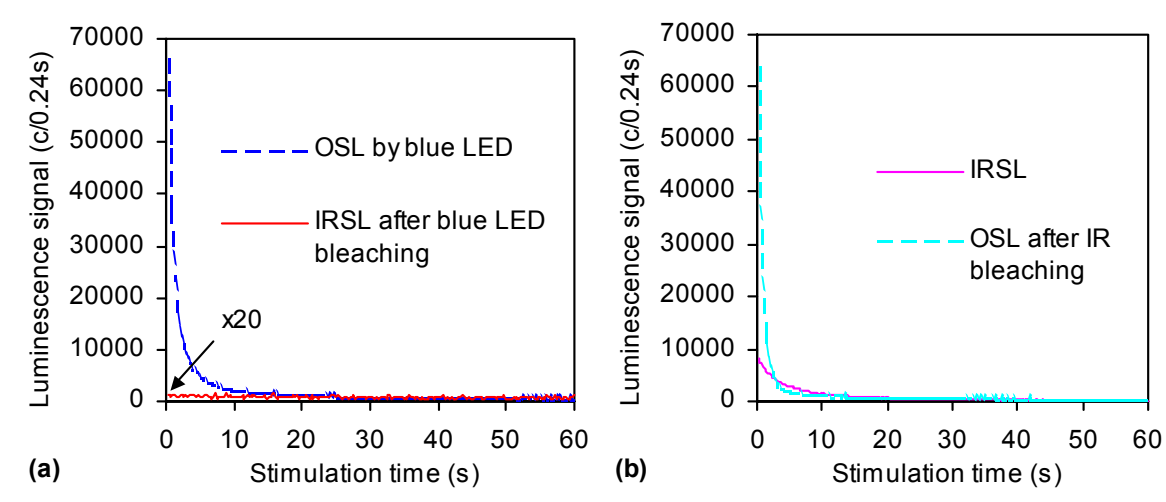

Fig. 1. Bleaching experiments. (a) A natural aliquot of un-etched grains was stimulated by blue LED stimulation for $60 \mathrm{~s}$ at $130^{\circ} \mathrm{C}$, then stimulated immediately by IR for $60 \mathrm{~s}$ at $130^{\circ} \mathrm{C}$. After blue LED stimulation, the IRSL has been reduced to background level. The IRSL shine-down curve has been multiplied by 20 for clarity; (b) Another aliquot of unetched grains was stimulated by IR stimulation for $60 \mathrm{~s}$ at $130^{\circ} \mathrm{C}$, then stimulated immediately by blue $L E D$ for $60 s$ at $130^{\circ} \mathrm{C}$. 
underestimation of post-IR BLSL $D_{e}$ (see Table 2) suggests that the IR stimulation cannot thoroughly remove the BLSL of feldspars. Duller and Bøtter-Jensen (1993) proposed that the GLSL of feldspars consisted of two types of traps, one could be reset by both the blue/green and IR stimulation, and another could be reset only by blue/green stimulation. Sanderson and Clark (1994) found that the BLSL of microcline could survive heating to $400^{\circ} \mathrm{C}$, whereas the IRSL was totally reset by heating to $350^{\circ} \mathrm{C}$. They proposed that the BLSL of feldspars has at least two components and that one has greater thermal stability than the IRSL.

\section{GROWTH CURVE SHAPE}

As the saturation dose of feldspars is much larger than that of quartz, their growth curves will differ accordingly. The growth curves for IRSL, post-IR BLSL and BLSL were constructed using the measurements of $D_{e}$ determi- nation described in the previous section for both fractions of "etched for 3 days" and "un-etched:quartz = 1:10". The growth curve for BLSL of pure quartz was also constructed (Fig. 2). The regeneration doses used were 5, 10, $15,25,50,100,150,0$, and $5 \mathrm{~Gy}$. The growth curves can be fitted properly using the saturating exponential function. The growth curve of IRSL has the largest $D_{o}$ value (at the point of $D_{o}$, the growth curve crosses value, which is $1 / \mathrm{e}$ bellow the saturation level), and the post-IR BLSL the smallest (Table 3). The contamination of feldspars in quartz will change the shape of growth curve for quartz BLSL. Other factors will also affect the shape of quartz BLSL growth curve. For example, annealing to high temperatures (e.g. $>360^{\circ} \mathrm{C}$ ) will reduce significantly the saturation dose for quartz BLSL (Lai et al., 2008).

It has been shown that a common growth curve exists for quartz OSL for loess (Roberts and Duller, 2004; Lai, 2006; Lai et al., 2007b). Roberts and Duller (2004) also reported that the growth curves of IRSL and post-IR OSL

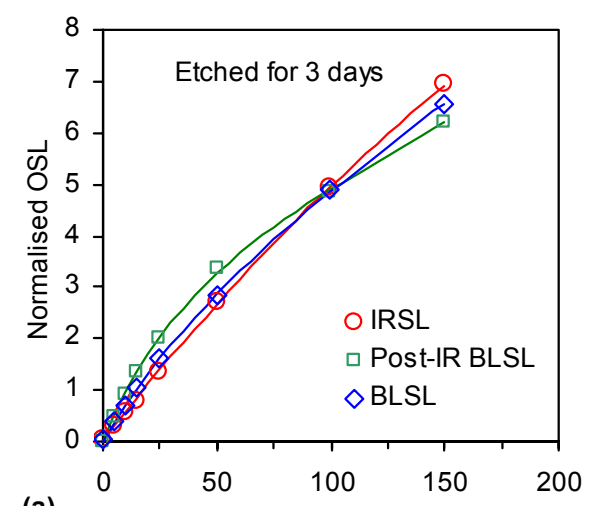

(a)

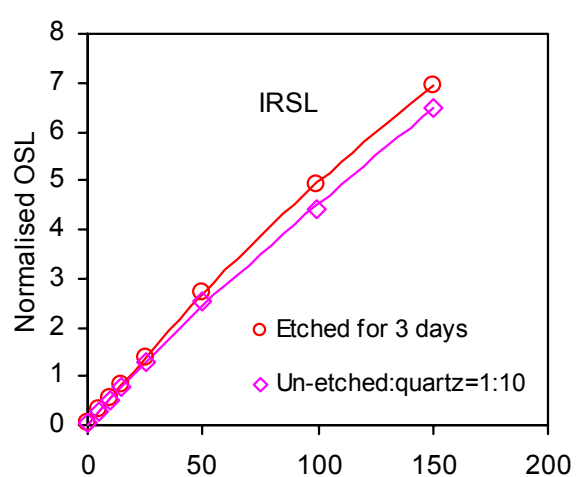

(c)

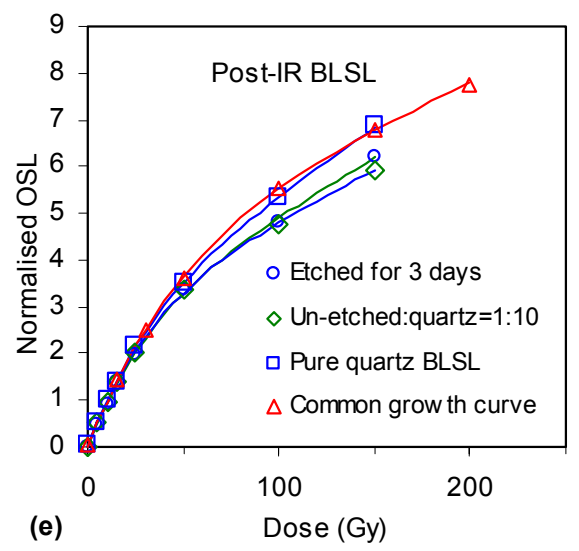

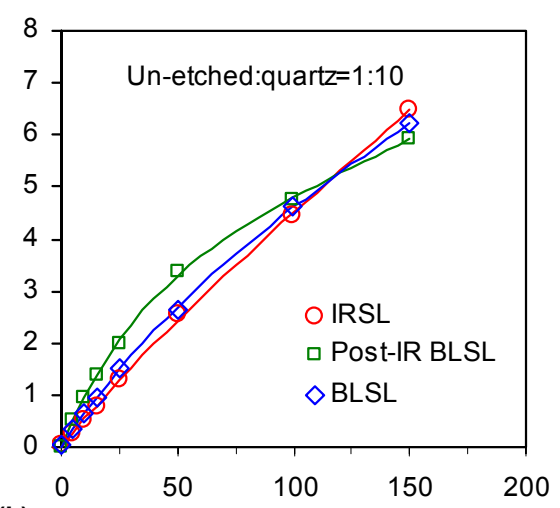

(b)

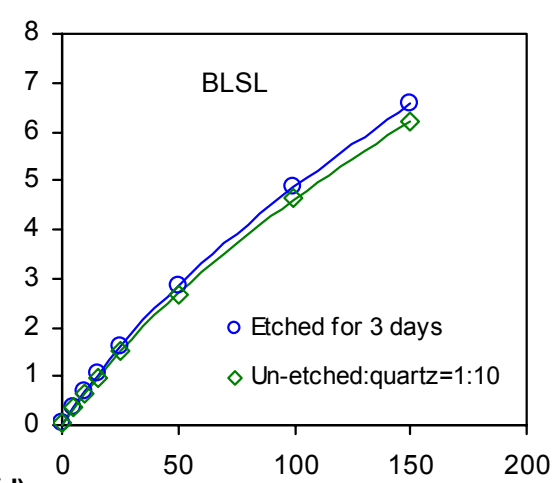

(d)

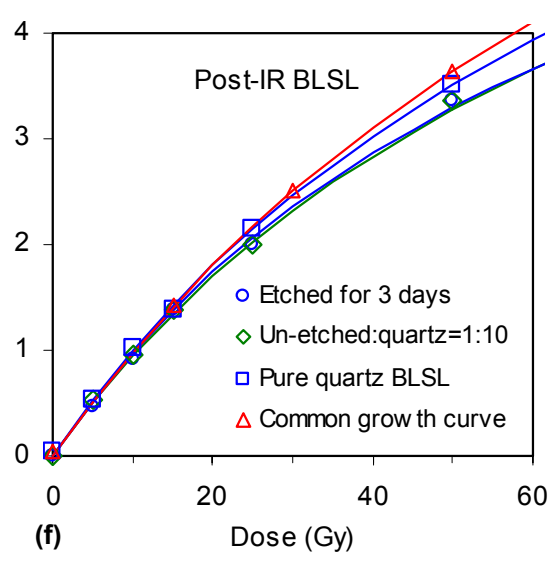

Fig. 2. Growth curves using regeneration doses of 5, 10,15, 25, 50,100, and $150 \mathrm{~Gy}$. (a) For the fraction of "etched for 3 days"; (b) For the fraction of "un-etched:quartz = 1:10"; (c) IRSL growth curves for both fractions; (d) BLSL growth curves for both fractions; (e) Post-IR BLSL growth curves for both fractions, together with the growth curve of pure quartz BLSL for this sample (open square) and the common growth curve of quartz BLSL for loess samples from different continents reported by Lai et al. (2007b) (open triangle, normalised with respect to the size of test dose). (f) Enlarged from (e) for clarify of low dose range. In all cases the error bars are smaller than the symbols. 
Table 3. Parameters for the fitting of growth curves using the form of $Y=k\left(1-\exp \left(-X / D_{0}\right)\right)$.

\begin{tabular}{|c|c|c|c|c|c|c|c|}
\hline & \multicolumn{3}{|c|}{ Etched for 3 days } & \multicolumn{3}{|c|}{$K F: Q=1: 10$} & Quartz \\
\hline & IRSL & BLSL & P-BLSL* & IRSL & BLSL & P-BLSL* & BLSL \\
\hline k & 19.0 & 10.8 & 7.1 & 20.3 & 10.5 & 6.5 & 8.2 \\
\hline$D_{0}$ & 330.1 & 160.8 & 78.9 & 392.9 & 168.2 & 69.4 & 87.6 \\
\hline
\end{tabular}

${ }^{*} \mathrm{P}-\mathrm{BLSL}$ is the post-IR BLSL

are identical for doses within 25 Gy using fine grain of 4-11 $\mu \mathrm{m}$, and that beyond 25 Gy post-IR OSL saturates faster. The result here is different, and the two growth curves are different for all dose range (0-150 Gy; Figs. 2a, b). Within $25 \mathrm{~Gy}$, the test-dose normalised signal grows quicker for post-IR BLSL than for IRSL, but similarly to pure quartz BLSL (Figs. 2e, f). When normalised with respect to the size of the test dose, the shape of pure quartz BLSL growth curve for this sample is identical to the common growth curve for loess samples from different continents reported by Lai et al. (2007b; Fig. 2e) in which a test dose of 11.3 Gy was used.

\section{CONCLUSIONS}

1. The $D_{e}$ determined using feldspar in Chinese loess is obviously underestimated, and IRSL has a greater underestimation than BLSL. For aliquots with no fluorosilicic acid etching, an IRSL $D_{e}$ underestimation of $\sim 30 \%$ is observed for a sample with an expected age of $\sim 22 \mathrm{ka}, \sim 19 \%$ underestimation for BLSL, and $\sim 10 \%$ for post-IR BLSL. For quartz BLSL, the contamination of feldspars will inevitably lead to $D_{e}$ and age underestimation. We suggest that IR-checking should be performed for every single aliquot at the end of SAR procedures. An aliquot should be excluded from the final $D_{e}$ calculation if obvious IRSL signal was observed.

2. Blue LED stimulation can zero both IRSL and BLSL signals of feldspars, while IR stimulation seems not to be able to zero the BLSL of feldspars for the sample under study.

3. The growth curve shape of the post-IR BLSL is very different from that of the IRSL for all doses; but it is identical to that of the pure quartz BLSL for doses less than $\sim 25 \mathrm{~Gy}$. The contamination of feldspars in quartz will change the shape of growth curve for quartz BLSL.

\section{ACKNOWLEDGEMENTS}

ZPL thanks the Alexander von Humboldt Foundation for a research fellowship. We thank Michael Blair and Nicole Klasen for proof-reading and helpful comments, and Alexander Fülling for help in the laboratory. Helpful comments from two anonymous referees are appreciated. Also supported by One-Hundred Talent Project, CAS.

\section{REFERENCES}

Banerjee D, Murray AS, Bøtter-Jensen L and Lang A, 2001. Equivalent dose estimation using a single aliquot of polymineral fine grains.
Radiation Measurements 33(1): 73-93, DOI 10.1016/S13504487(00)00101-3.

Blair MW, Yukihara EG and McKeever SWS, 2005. Experiences with single-aliquot OSL procedures using coarse-grain feldspars. $R a$ diation Measurements 39(4): 361-374, DOI 10.1016/j.radmeas.2004.05.008.

Buylaert JP, Vandenberghe D, Murray AS, Huot S, De Corte F, Van den Haute P, 2007. Luminescence dating of old (>70 ka) Chinese loess: A comparison of single-aliquot OSL and IRSL techniques. Quaternary Geochronology 2(1-4): 9-14, DOI 10.1016/j.quageo.2006.05.028.

Duller GAT and Bøtter-Jensen L, 1993. Luminescence from potassium feldspars stimulated by infrared and green light. Radiation Protection Dosimetry 47: 683-688.

Galloway RB, 1994. Comparison of the green- and infrared-stimulated luminescence of feldspar. Radiation Measurements 23(2-3): 617620, DOI 10.1016/1350-4487(94)90109-0.

Jain M and Singhvi AK, 2001. Limits to depletion of blue-green light stimulated luminescence in feldspars: implications for quartz dating. Radiation Measurements 33(6): 883-892, DOI 10.1016/S1350-4487(01)00104-4.

Krbetschek MR, Gotze J, Dietrich A and Traumann T, 1997. Spectral information from minerals relevant for luminescence dating. $R a-$ diation Measurements 27(5-6): 695-748, DOI 10.1016/S13504487(97)00223-0.

Lai Z-P, 2006. Testing the use of an OSL standardised growth curve (SGC) for $\mathrm{D}_{\mathrm{e}}$ determination on quartz from the Chinese Loess Plateau. Radiation Measurements 41(1): 9-16, DOI 10.1016/j.radmeas.2005.06.031.

Lai Z-P and Wintle AG, 2006. Locating the boundary between the Pleistocene and the Holocene in Chinese loess using luminescence. The Holocene 16(6): 893-899, DOI 10.1191/0959683606hol980rr.

Lai Z-P, Wintle AG and Thomas DSG, 2007a. Rates of dust deposition between $50 \mathrm{ka}$ and $20 \mathrm{ka}$ revealed by OSL dating at Yuanbao on the Chinese Loess Plateau. Palaeogeography, Palaeoclimatology, $\begin{array}{llll}\text { Palaeoecology } & \text { 248(3-4): } & 431-439, & \text { DOI }\end{array}$ 10.1016/j.palaeo.2006.12.013.

Lai Z-P, Brückner H, Zöller L and Fülling A, 2007b. Existence of a common growth curve for silt-sized quartz OSL of loess from different continents. Radiation Measurements 42(9): 1432-1440, DOI 10.1016/j.radmeas.2007.08.006.

Lai Z-P, Brückner H, Zöller L and Fülling A, 2008. The effect of thermal treatment on the growth curve shape for OSL of quartz extracted from Chinese loess. Radiation Measurements, in press, DOI 10.1016/j.radmeas.2008.01.023.

Murray AS and Wintle AG, 2000. Luminescence dating of quartz using an improved single-aliquot regenerative-dose protocol. Radiation Measurements 32(1): 57-73, DOI 10.1016/S1350-4487(99)00253$\mathrm{X}$.

Murray AS and Wintle AG, 2003. The single aliquot regenerative dose protocol: potential for improvements in reliability. Radiation Measurements 37(4-5): 377-381, DOI 10.1016/S13504487(03)00053-2.Roberts HM and Duller GAT, 2004. Standardised growth curves for optical dating of sediment using multiplegrain aliquots. Radiation Measurements 38(2): 241-252, DOI 10.1016/j.radmeas.2003.10.001.

Roberts HM and Wintle AG, 2001. Equivalent dose determination for polymineral fine-grains using the SAR protocol: application to a Holocene sequence of the Chinese Loess Plateau. Quaternary Science Reviews 20(5-9): 859-863, DOI 10.1016/S02773791(00)00051-2.

Sanderson DCW and Clarke RJ, 1994. Pulsed photostimulated luminescence of alkali feldspars. Radiation Measurements 23(2-3): 633639, DOI 10.1016/1350-4487(94)90112-0.

Wallinga J, Murray AS and Bøtter-Jensen L, 2002. Measurement of the dose in quartz in the presence of feldspar contamination. Radiation Protection Dosimetry 101: 367-370.

Watanuki T, Murray AS and Tsukamoto S, 2003. A comparison of OSL ages derived from silt-sized quartz and polymineral grains from Chinese loess. Quaternary Science Reviews 22(10-13): 991-997, DOI 10.1016/S0277-3791(03)00053-2.

Wintle AG, 1973. Anomalous fading of thermoluminescence in mineral samples. Nature 245(5421): 143-144, DOI 10.1038/245143a0. 